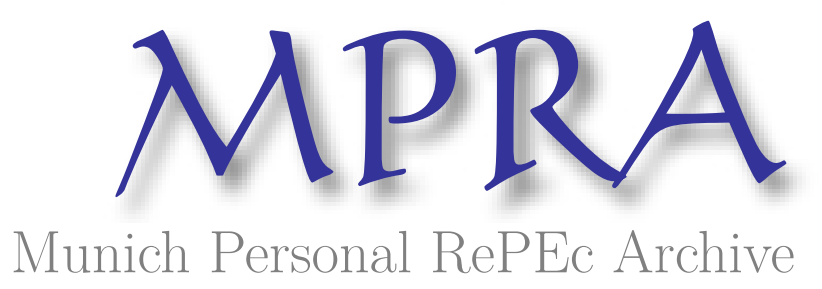

\title{
Real Estate, the External Finance Premium and Business Investment: A Quantitative Dynamic General Equilibrium Analysis
}

Jin, Yi and Leung, Charles Ka Yui and Zeng, Zhixiong Monash University, City University of Hong Kong

November 2010

Online at https://mpra.ub.uni-muenchen.de/26722/ MPRA Paper No. 26722, posted 16 Nov 2010 16:58 UTC 


\title{
Real Estate, the External Finance Premium and Business Investment: A Quantitative Dynamic General Equilibrium Analysis
}

\author{
Yi Jin* \\ Department of Economics \\ Monash University \\ Charles Ka Yui Leung ${ }^{\dagger}$ \\ Department of Economics and Finance \\ City University of Hong Kong \\ Zhixiong Zeng ${ }^{\ddagger}$ \\ Department of Economics \\ Monash University
}

November 2010

\begin{abstract}
This paper studies the connection between the capital market and the real estate market. Empirically, we find that positive real house price shocks lower the external finance premium and stimulate nonresidential investment and real GDP. Our theoretical framework is able to mimic the volatility of the external finance premium, the relative price of real estate and capital, and the investment in real estate and capital. It also captures the cyclicality of the external finance premium and of real estate prices. The contribution of real estate price fluctuations to the variability of the external finance premium and the GDP is confirmed to be significant.
\end{abstract}

JEL Classification Number: E44, D82, R21, R31

Keywords: External Finance Premium, Residential and Corporate Real Estate, Capital Market Imperfections, Equilibrium Default, Real Estate Price Volatility.

\footnotetext{
${ }^{*}$ Department of Economics, Monash University, 900 Dandenong Road, Caulfield East, VIC 3145, Australia. Phone: +61-3-99032042, Fax: +61-3-99031128, Email: yi.jin@monash.edu, Homepage: http://users.monash.edu.au/ ${ }^{\sim}$ yij/.

${ }^{\dagger}$ Corresponding author. Department of Economics and Finance, The City University of Hong Kong, Kowloon Tong, Hong Kong SAR, China. Phone: (852) 2788-9604, Fax: (852) 2788-8842, Email: kycleung@cityu.edu.hk.

${ }^{\ddagger}$ Department of Economics, Monash University, 900 Dandenong Road, Caulfield East, VIC 3145, Australia. Phone: +61-3-99034517, Fax: +61-3-99031128, Email: zhixiong.zeng@monash.edu, Homepage: http://faculty.ccer.edu.cn/zxzeng/.
} 


\section{Introduction}

This paper attempts to study a natural but perhaps under-explored connection between the imperfect capital market and the real estate market. An emerging literature indicates that the real estate market is closely related to the business cycles (Greenwood and Hercowitz, 1991; Iacoviello, 2005; Jin and Zeng, 2004; Leung, 2004). It is also well known that the imperfect capital market plays an important role in the propagation of shocks over the business cycles (Bernanke and Gertler, 1995; Bernanke, Gertler and Gilchrist, 1999; Hubbard, 1998). Thus, it is reasonable to conjecture that the imperfect capital market may also be related to the housing market. To explore this possibility, this paper follows the literature in employing the external finance premium $(E F P)$ as a measure of the changing conditions of the credit market. Bernanke and Gertler (1995, p.28) define the EFP as "the difference in cost between funds raised externally and funds generated internally." It is regarded as a key indicator of the extent of credit market imperfections in the literature (Bernanke, Gertler, and Gilchrist, 1999 (henceforth BGG); Carlstrom and Fuerst, 1997; and Fisher, 1999). In practice, borrowers may default, and lenders will charge a premium on the debt contract, and thus the EFP naturally arises. As BGG are pioneers of modeling the EFP in a dynamic general equilibrium setting, this paper extends the model of BGG to include the real estate market.

To investigate the possible linkage between the capital market imperfection (proxied by the EFP) and the real estate market more formally, we will run a vector autoregression $(V A R) .{ }^{1}$ A merit of VAR is that it allows the variables to interact with one another in

\footnotetext{
${ }^{1}$ Among others, see Sims (1980) for more discussion on this point.
} 
a dynamic manner. In particular, our VAR model contains the variables of the log of real GDP $(G D P Q)$, the log of real OFHEO price $(P H)^{2}$, the external finance premium $(E F P)$, which is computed as the prime bank lending rate minus the 3-month T-bill rate and expressed in percentage points, and the log of real nonresidential investment $(N R I)$, all of them are calculated on quarterly figures. Limited by the data availability, the sample period is from 1975Q1 to 2008Q2. We use a simple short-run recursiveness identification scheme to identify the impulse responses to structural disturbances (see Christiano, Eichenbaum, and Evans, 1999). As our results are robust against the ordering of these variables in the $V A R$, we present results based on the ordering of $G D P Q, P H$, $E F P$, and NRI. The number of lags is set to 4 according to the Akaike Information Criterion (AIC) and the Schwarz Information Criterion (SIC). The impulse responses are presented in Figure 1. First, a positive shock to real GDP drives real house prices and nonresidential investment up. At the same time, it drives the external finance premium down, corroborating the previous finding in the literature of the countercyclicality of EFP. Second, a positive real house price shock lowers the external finance premium and stimulates nonresidential investment and real GDP, though the effect on $N R I$ is not statistically significant. This suggests that an under-explored linkage between the EFP and the housing market may nevertheless be worth further investigation. Third, an unexpected increase in the EFP would depress the real GDP without having a significant impact on house prices. Combining the second and the third results suggests that the causality is more likely to be from the housing market to the capital market, rather than the other way

\footnotetext{
${ }^{2}$ The nominal OFHEO prices are deflated by NIPA's implicit price deflator for personal consumption expenditure.
} 
round. Finally, a positive shock to nonresidential investment raises the external finance premium, presumably through making firms more financially leveraged.

(Insert Figure 1 about here)

These results are consistent with the view that real estate contributes significantly to business financing in general. As recognized by Manove, Padilla and Pagano (2001, p.728), "In the United States, approximately $40 \%$ of the small business loans and almost $60 \%$ of their value are guaranteed and/or secured with personal assets... Collateral requirements are even larger for small business in developing countries and in backward regions of developed economies." Accordingly, this paper will study how real estate prices interact with the external finance premium, business investment, and the aggregate economy.

In addition, this paper will explicitly introduce corporate real estate (CRE) into an otherwise standard dynamic stochastic general equilibrium model (DSGE). The significance of real estate as a share of the total assets of corporations has long been discussed. For instance, Zeckhauser and Silverman (1983) estimate that corporate real estate constitutes between $25-40 \%$ of the total assets of firms on average. Later studies have confirmed this finding (Veale, 1989; Liow, 1995; Du et al., 2008; Dong et al., 2010) Interestingly, CRE is absent in most, if not all of the DSGE models. In this paper, CRE plays an important role as it is both production and collateral against which firms can borrow from the banks. In practice, although the value of CRE is typically not perfectly correlated with firm performance, banks welcome such asset as collateral and lend greater amount to firms than 
they would in the absence of CRE. Unfortunately, there is a drawback. When the value of CRE declines along with the economy, debt capacity also shrinks. This clearly affects investment at the firm level and, eventually, at the aggregate level. Thus, introducing CRE into a DSGE model provides an additional propagation mechanism to link together the real estate market and the aggregate economy.

This paper is closely related to the emerging literature on housing and the macroeconomy. Muellbauer and Murphy (1997) study the turbulent United Kingdom housing market. Del Negro and Otrok (2007) confirm the recent increase in the importance of housing to the U.S. economy. Iacoviello and Minetti (2003) study the role of monetary policy shocks in house price fluctuations in Finland, Sweden and the UK. They find that the response of house prices to interest rate surprises is greater and more persistent in periods characterized by more liberalized financial markets. Iacoviello and Minetti (2008) employ a VAR approach to analyze the housing markets of Finland, Germany, Norway and the UK. They show a clear-cut relationship across the four countries between the presence of credit channels, the efficiency of housing finance, and the type of institutions active in mortgage provision. Almeida, Campello and Liu (2006) present cross-country evidence that differences in lending policies, such as the loan-to-value ratio, can affect the economy's sensitivity to monetary policy or income shocks. Lustig and van Nieuwerburgh (2005) find empirically that the value premium in the financial market varies systematically with the level of housing collateral in the economy. This paper complements the literature by formulating a stochastic dynamic general equilibrium model which explicitly links the imperfect capital market faced by firms (measured by the EFP), the house prices faced by the households, and the aggregate economy. 
This paper is also related to a large literature on the house price dynamics, and how it is related to the market fundamentals, including Andrew and Meen (2003), Capozza, Hendershott and Mack (2004), Clapp, Dolde and Tirtiroglu (1995), Clayton (1996), Gallin (2006), among others. This paper builds on their insights and build a DSGE model where the house price dynamics, as well as its relationship with the economic fundamentals are all determined at the equilibrium endogenously.

The organization of this paper is straightforward. The next section presents the model. Different agents in the model are then explained sequentially. The calibration section explains how the parameter values are assigned. This is followed by the quantitative results and a number of robustness checks. The final section concludes the paper.

\section{The Model}

Our model builds on the work of BGG and extends it to include corporate and residential real estate. Due to the similarities of the two models and the limited space available, we will provide a brief outline of our model. Once again, it is a dynamic, stochastic general equilibrium model (DSGE), with credit market imperfections. Time is discrete and the horizon is infinite. There are three types of agents in this economy, households, entrepreneurs, and financial intermediaries. Households work, consume, purchase houses, and save. Their savings are directed to entrepreneurs via financial intermediaries. Loan contracts are signed between entrepreneurs and financial intermediaries to finance entrepreneurial investment, in a way that compensates for default risks. In these contracts entrepreneurial assets, including productive capital and corporate real estate, serve as collateral. 
To understand the mechanism underlying this model, let us consider a positive productivity shock on aggregate total factor productivity (TFP). As it is common in other DSGE models, it will improve the productivity of firms, and it also increases the income of the households. Clearly, the first effect will lead to a decrease in the probability of firms becoming bankrupt. Moreover, the increase in household income will lead to an increase in housing demand, and hence an increase in real estate prices. Because the commercial real estate is part of the collateral of firms, an increase in real estate prices will further depress the probability of firms becoming bankrupt. As a result, less bankruptcy will occur and resources can be used for productive purposes. In other words, the improvement in the aggregate TFP will directly (through the firms' production) and indirectly (through household income and real estate prices) increase the "debt capacity" of entrepreneurs, which tends to encourage investment. As a result, aggregate investment and GDP will be stimulated. Figure 2 summarizes the discussion. Thus, our model provides an unifying framework in which the real estate market, the imperfect capital market and aggregate output are closely linked. ${ }^{3}$ The following sections will formalize these intuitions.

(Insert Figure 2 about here)

\footnotetext{
${ }^{3}$ Previous literature such as Shleifer and Vishny (1992), Wang, Young and Zhou (2002), Brown, Ciochetti and Riddiough, (2006), among others, focus on the production sector and do not consider the housing market.
} 


\subsection{Entrepreneurs}

When describing entrepreneurial activities it is helpful to outline a sequence of events within a generic time period in the following manner. (1) A fraction $1-\gamma, \gamma \in(0,1)$ of entrepreneurs die. New entrepreneurs are born in the same measure. Following BGG, we assume that the dying entrepreneurs consume their net worth before they leave the scene. The living entrepreneurs are engaged in production and investment activities. (2) Entrepreneurs use the capital and productive real estate they have accumulated and the labor they hire to produce output. (3) Repayments are made on loans borrowed in the previous period. Depending on the returns realized returns on their capital, entrepreneurs can be either solvent or insolvent. Insolvent entrepreneurs go bankrupt and a bankruptcy loss is incurred. ${ }^{4}$ (4) Solvent entrepreneurs sign contracts with financial intermediaries to purchase additional capital and real estate. The contracts specify the amounts borrowed and the terms of repayment. The sequence of events is described in Table 1.

[Insert Table 1 here.]

Following BGG, individual entrepreneurs face aggregate and idiosyncratic shocks to their asset returns. Our model differs from BGG in that we distinguish commercial real estate from physical capital (such as machinery and equipment). Since the price processes of real estate and capital are different, which introduces another channel for productivity

\footnotetext{
${ }^{4}$ We assume that bankrupt firms are reorganized and receive an infinitesimal amount of transfer from the government to maintain a positive amount of net worth. This makes the number of entrepreneurs/firms constant over time.
} 
shocks to affect economic performance. Accordingly, we require notation to formalize this idea. Let $K_{t}^{j}, H_{t}^{e j}, M_{t}^{j}$, and $\Omega_{t}^{j}$ represent entrepreneur $j$ 's capital stock, commercial real estate, asset value, and gross return to asset in period $t$, respectively. Then

$$
M_{t}^{j}=Q_{t-1}^{k} K_{t}^{j}+Q_{t-1}^{h} H_{t}^{e j}
$$

and

$$
\Omega_{t}^{j}=\omega_{t}^{j} R_{t}^{a} M_{t}^{j}
$$

where $Q_{t-1}^{k}\left(Q_{t-1}^{h}\right)$ is the price of capital (real estate) prevailing in period $t-1$ when entrepreneur $j$ acquires $K_{t}^{j}\left(H_{t}^{e j}\right), R_{t}^{a}$ is the aggregate rate of return on assets from period $t-1$ to $t$, and $\omega_{t}^{j}$ is an idiosyncratic shock specific to entrepreneur $j$. We derive a condition that determines $R_{t}^{a}$ below.

We assume that entrepreneur $j$ operates a Cobb-Douglas production technology:

$$
Y_{t}^{j}=A_{t}\left[\omega_{t}^{j}\left(K_{t}^{j}\right)^{\phi}\left(H_{t}^{e j}\right)^{1-\phi}\right]^{\alpha}\left(L_{t}^{j}\right)^{1-\alpha}
$$

where $L_{t}^{j}$ is labor input, $A_{t}$ is aggregate total factor productivity, and $\omega_{t}^{j}$ is an idiosyncratic shock specific to entrepreneur $j$ in period $t$. We assume that $\omega_{t}^{j}$ is distributed identically and independently across entrepreneurs and over time, and has unit mean and c.d.f. (cumulative distribution function) $F(\omega)$. Since all entrepreneurs choose identical ratio of capital (and real estate) to labor, entrepreneur $j$ 's revenue, net of the labor cost, can be written as $\omega_{t}^{j} \frac{\alpha Y_{t}}{K_{t}^{\phi}\left(H_{t}^{e}\right)^{1-\phi}}\left(K_{t}^{j}\right)^{\phi}\left(H_{t}^{e j}\right)^{1-\phi}$, where $K_{t}, H_{t}^{e}$, and $Y_{t}$ denote aggregate capital, aggregate entrepreneurial real estate, and aggregate output, respectively, where

$$
Y_{t}=A_{t}\left[K_{t}^{\phi}\left(H_{t}^{e}\right)^{1-\phi}\right]^{\alpha} L_{t}^{1-\alpha}
$$


Notice that the term $\frac{\alpha Y_{t}}{K_{t}^{\phi}\left(H_{t}^{e}\right)^{1-\phi}}$ is like an economy-wide shock from an individual firm point of view. We assume that the aggregate total factor productivity $\left\{A_{t}\right\}$ follows an $A R(1)$ process:

$$
\ln A_{t+1}=\rho_{A} \ln A_{t}+\varepsilon_{A, t+1}
$$

where $\varepsilon_{A, t+1} \sim N\left(0, \sigma_{A}^{2}\right)$.

In period $(t-1)$ entrepreneur $j$ contracts with financial intermediaries on the amount of borrowing, which along with existing entrepreneurial net worth gives the total value of entrepreneurial assets to be carried over to period $t$. Given this, the entrepreneur is free to choose her portfolio, i.e., division of total asset $M_{t}^{j}$ into $K_{t}^{j}$ and $H_{t}^{e j}$, to maximize its expected return from period $t-1$ to $t$. Note that it would be equivalent to postulate that entrepreneurs and financial intermediaries contract in period $(t-1)$ on the optimal bundle of $K_{t}^{j}$ and $H_{t}^{e j}$, in addition to the optimal amount of $M_{t}^{j}$. The formulation adopted here allows us to derive an expression for the return to asset that nests the expression in $B G G$ as a special case. Given $M_{t}^{j}$, the entrepreneur solves the following problem:

$$
\max _{K_{t}^{j}, H_{t}^{e j}} E_{t-1}\left\{\frac{\alpha Y_{t}}{\left(K_{t}\right)^{\phi}\left(H_{t}^{e}\right)^{1-\phi}}\left(K_{t}^{j}\right)^{\phi}\left(H_{t}^{e j}\right)^{1-\phi}+Q_{t}^{k}\left(1-\delta^{k}\right) K_{t}^{j}+Q_{t}^{h}\left(1-\delta^{h}\right) H_{t}^{e j}\right\}
$$

subject to

$$
Q_{t-1}^{k} K_{t}^{j}+Q_{t-1}^{h} H_{t}^{e j} \leq M_{t}^{j}
$$

where $\delta^{k}$ and $\delta^{h}$ are the rates of depreciation for capital and real estate, respectively. The return on assets includes output produced and the market value of the un-depreciated portions of entrepreneurial capital and real estate. ${ }^{5}$ One can show that the Lagrangian

\footnotetext{
${ }^{5}$ Note that the expectation in (4) is conditional on period $t-1$ aggregate information. The term $\omega_{t}^{j}$ is absent within the braces since it is orthogonal to period $t$ aggregate shock and has unit mean.
} 
multiplier for constraint (5) is identical for all entrepreneurs. By the envelope theorem, this multiplier, denoted by $\tilde{R}_{t}^{a}$, is also the expected rate of return on assets. As it is common for all entrepreneurs, we call it the aggregate expected rate of return on assets. Let $R_{t}^{a}$ denote the realized aggregate return to asset. Thus, we have $\tilde{R}_{t}^{a}=E_{t-1}\left(R_{t}^{a}\right) . R_{t}^{a}$ satisfies the following equations:

(The derivations can be found in Appendix A.)

$$
\begin{aligned}
& E_{t-1}\left[\frac{\alpha Y_{t}}{\left(K_{t}\right)^{\phi}\left(H_{t}^{e}\right)^{1-\phi}} \phi\left(\frac{K^{j}}{H^{e j}}\right)^{\phi-1}+Q_{t}^{k}\left(1-\delta^{k}\right)\right]=E_{t-1}\left(R_{t}^{a}\right) Q_{t-1}^{k}, \\
& E_{t-1}\left[\frac{\alpha Y_{t}}{\left(K_{t}\right)^{\phi}\left(H_{t}^{e}\right)^{1-\phi}}(1-\phi)\left(\frac{K^{j}}{H^{e j}}\right)^{\phi}+Q_{t}^{h}\left(1-\delta^{h}\right)\right]=E_{t-1}\left(R_{t}^{a}\right) Q_{t-1}^{h}, \\
& {\left[R_{t}^{a} Q_{t-1}^{k}-Q_{t}^{k}\left(1-\delta^{k}\right)\right]^{\phi}\left[R_{t}^{a} Q_{t-1}^{h}-Q_{t}^{h}\left(1-\delta^{h}\right)\right]^{(1-\phi)}=\phi^{\phi}(1-\phi)^{1-\phi} \frac{\alpha Y_{t}}{\left(K_{t}\right)^{\phi}\left(H_{t}^{e}\right)^{1-\phi}} . }
\end{aligned}
$$

Notice that (7) is the result of the maximization of (4). This means that $R_{t}^{a}$ is what the entrepreneur would obtain on her capital if she were allowed to optimally divide $M_{t}^{j}$ between $K_{t}^{j}$ and $H_{t}^{e j}$ after observing the period $t$ aggregate shock (but before observing the idiosyncratic shock). Having defined the aggregate return on assets, entrepreneur $j$ 's realized idiosyncratic return in period $t$ can be written as $\Omega_{t}^{j}=\omega_{t}^{j} R_{t}^{a} M_{t}^{j}$, which is (1).

Importantly, condition (7) nests BGG's expression for the rate of return on capital as a special case. Simply setting $\phi=1$ (there is no real estate in the entrepreneurial sector) yields:

$$
R_{t}^{a}=\frac{\alpha Y_{t} / K_{t}+Q_{t}^{k}\left(1-\delta^{k}\right)}{Q_{t-1}^{k}}
$$

as appeared in BGG. 


\section{$2.2 \quad$ Financial Contracting}

Entrepreneur $j$, if solvent, signs a contract with a financial intermediary to finance her investments in productive capital and real estate. Similar to BGG, the entrepreneur's financing equation reads:

$$
Q_{t}^{k} K_{t+1}^{j}+Q_{t}^{h} H_{t+1}^{e j}=\Omega_{t}^{j}-Z_{t}^{j} B_{t}^{j}+B_{t+1}^{j},
$$

where $B_{t+1}^{j}$ is the amount borrowed in period $t$. It is also apparent from (8) that $M_{t+1}^{j}=$ $\Omega_{t}^{j}-Z_{t}^{j} B_{t}^{j}+B_{t+1}^{j}$. Here $N_{t+1}^{j} \equiv \Omega_{t}^{j}-Z_{t}^{j} B_{t}^{j}$ constitutes the entrepreneur's net worth. Hence we also have

$$
M_{t+1}^{j}=N_{t+1}^{j}+B_{t+1}^{j}
$$

i.e. the asset value equals to the sum of the net worth and borrowing.

We will now analyze the financial contracting decision of an individual entrepreneur. To ease the notations, we omit the superscript $j$ in this subsection. Given the amount of entrepreneurial net worth, the contract specifies the amount of borrowing $B_{t+1}$ (and hence the desired asset value $M_{t+1}$ ) and a state-contingent payment schedule. Here we follow the costly state verification (CSV) tradition of Townsend (1979) in modelling credit market imperfections. ${ }^{6}$ We assume that only entrepreneurs can observe the realizations of the idiosyncratic shock $\omega_{t+1}$ without cost, while financial intermediaries have to expend a verification cost (interpretable as the cost of bankruptcy, as in Gale and Hellwig, 1985) to know the true value. The cost is assumed to be proportional to entrepreneurial asset return $\Omega_{t+1}$, the factor of proportionality being $\mu \in(0,1) .^{7}$

\footnotetext{
${ }^{6}$ The CSV formulation has been widely used in the literature, including Gale and Hellwig (1985), Williamson (1986, 1987), Mookherjee and Png (1989), Boyd and Smith (1997), Huybens and Smith (1998), Smith and Wang (1998), among others.

${ }^{7}$ For evidence of the "fire-sale discount," see Shleifer and Vishny (1992), Espen Eckbo and Thorburn
} 
We follow three steps in analyzing the optimal contract. First, given the amount of borrowing $B_{t+1}$, the optimal form of contract is the standard debt contract, as shown by Gale and Hellwig (1985) and Williamson (1986). The contract can be characterized by a nondefault interest rate $Z_{t+1}$. When the entrepreneur is solvent in period $t+1$, i.e., $\Omega_{t+1} \geq Z_{t+1} B_{t+1}$, she pays the fixed amount $Z_{t+1} B_{t+1}$ to the financial intermediary. No monitoring occurs in this case. Otherwise the intermediary monitors and confiscates all the entrepreneur's revenue and incurs verification cost $\mu \Omega_{t+1}$. Given the aggregate rate of return $R_{t+1}^{a}$, the cutoff level of $\Omega_{t+1}$ corresponds to a cutoff value $\bar{\omega}_{t+1}$ for the idiosyncratic risk, which satisfies

$$
\bar{\omega}_{t+1} R_{t+1}^{a} M_{t+1}=Z_{t+1} B_{t+1} .
$$

Under the debt contract, the expected payment from the entrepreneur to the financial intermediary is given by $R_{t+1}^{a} M_{t+1} \Gamma\left(\bar{\omega}_{t+1}\right)$, where

$$
\Gamma(\bar{\omega}) \equiv[1-F(\bar{\omega})] \bar{\omega}+G(\bar{\omega})
$$

with

$$
G(\bar{\omega}) \equiv \int_{0}^{\bar{\omega}} \omega d F(\omega) .
$$

Recall that $\omega$ is distributed i.i.d., with the c.d.f. $F(\omega)$. Thus, $[1-F(\bar{\omega})]$ is the probability that $\omega$ takes on a value at least as large as $\bar{\omega}$ (and when this is the case, the entrepreneur will be solvent), and $G(\bar{\omega})$ is the expected value of $\omega$, provided that $\omega$ takes on a value not larger than $\bar{\omega}$ (and when this is the case, the entrepreneur will be insolvent). Hence (2008), among others. 
the entrepreneur's expected return is $R_{t+1}^{a} M_{t+1}\left[1-\Gamma\left(\bar{\omega}_{t+1}\right)\right]$, while the intermediary's expected return, net of monitoring cost, is given by $R_{t+1}^{a} M_{t+1}\left[\Gamma\left(\bar{\omega}_{t+1}\right)-\mu G\left(\bar{\omega}_{t+1}\right)\right] .{ }^{8}$

Following the procedures of BGG, we now proceed to the second step, which is to determine the risky loan rate $Z_{t+1}$. With the presence of aggregate uncertainty, $\bar{\omega}_{t+1}$ will in general depend on the ex post realization of $R_{t+1}^{a}$. We assume that entrepreneurs are risk-neutral while households, who are the owners of the financial intermediaries, are risk-averse. As BGG argue, this assumption leads to a simple contract structure. Because the entrepreneur cares only about the mean return on her wealth, she is willing to bear all the aggregate risk, and thus willing to guarantee the lender a return that is free of any systematic risk, i.e., conditional on the ex post realization of $R_{t+1}^{a}$, the borrower offers a state-contingent non-default payment that guarantees the lender a rate of return equal in expected value (the expectation taken over the distribution of the idiosyncratic entrepreneurial risk) to the riskless rate. ${ }^{9}$ Put differently, the following equation must hold for all possible realizations of $R_{t+1}^{a}$ :

$$
\left[\Gamma\left(\bar{\omega}_{t+1}\right)-\mu G\left(\bar{\omega}_{t+1}\right)\right] R_{t+1}^{a} M_{t+1}=R_{t+1}\left(M_{t+1}-N_{t+1}\right) .
$$

Equation (13) delivers a set of restrictions on $\bar{\omega}_{t+1}$, one for each realization of $R_{t+1}^{a}$. With the existence of aggregate uncertainty, it effectively pins down the risky loan rate $Z_{t+1}$, and hence the external finance premium $\left(E F P_{t+1} \equiv Z_{t+1}-R_{t+1}\right)$, to the aggregate conditions. In particular, the adjustment of the loan rate exhibits a countercyclical pattern. A realization of $R_{t+1}^{a}$ that is higher than expected reduces $\bar{\omega}_{t+1}$ and therefore $Z_{t+1}$.

\footnotetext{
${ }^{8}$ Note that the expected returns of the entrepreneur and the intermediary sum up to $R_{t+1}^{a} M_{t+1}\left[1-\mu G\left(\bar{\omega}_{t+1}\right)\right]$, where $\mu G\left(\bar{\omega}_{t+1}\right) R_{t+1}^{a} M_{t+1}$ reflects the deadweight loss, or agency cost, that arises from informational asymmetry.

${ }^{9}$ The only residual risk the lender bears arises from the idiosyncratic shock $\omega_{t+1}$, and is thus diversifiable. Diversification by intermediaries implies that households earn the riskless rate on their savings.
} 
The optimal amount of borrowing $B_{t+1}$ remains to be determined, which is the last step. By equation (9), this problem corresponds to the desired value of asset $M_{t+1}$. The nondefault interest rate, and hence the cutoff for the idiosyncratic risk $\bar{\omega}_{t+1}$, will be a function of the aggregate rate of return on asset $R_{t+1}^{a}$. The optimal contract solves the following problem:

$$
\max _{M_{t+1},\left\{\bar{\omega}_{t+1}\right\}} E_{t}\left\{\left[1-\Gamma\left(\bar{\omega}_{t+1}\right)\right] R_{t+1}^{a} M_{t+1}\right\}
$$

subject to the constraint that (13) holds for all realizations of $R_{t+1}^{a}$. In (14) - (13) the expectation is taken over the distribution of aggregate shocks.

Solving the problem (14), we obtain the demand schedule for asset:

$$
M_{t+1}=\psi\left(s_{t}\right) N_{t+1},
$$

where $\psi(\cdot)$ is an increasing function of the wedge between the expected rate of return to asset and the safe rate, i.e., $s_{t} \equiv E_{t} R_{t+1}^{a} / R_{t+1} \cdot{ }^{10}$ Equation (15) describes the critical link between entrepreneurial asset demand and financial conditions, as measured by $s_{t}$, and by entrepreneurial net worth, $N_{t+1}$. For a detailed description of the solution to the optimal contract problem, see Appendix B.

\subsection{Households}

We have completed the description of the entrepreneurs and their financial contract with the financial intermediaries. Now we turn to the household side of the model economy,

\footnotetext{
${ }^{10}$ Notice that at the time $t$, both $E_{t} R_{t+1}^{a}$ and the riskfree rate $R_{t+1}$ are known. Thus, $s_{t} \equiv E_{t} R_{t+1}^{a} / R_{t+1}$ can be interpreted as an "ex ante measure" of the credit market condition. In contrast, the EFP that we uses in the paper, can be interpreted as an "ex post measure."
} 
which is relatively standard. The representative household problem maximizes the expected value of the discounted sum of utility, subject to the budget constraints. Formally, the household solves the following problem:

$$
\begin{gathered}
\max _{\left\{C_{t}, H_{t+1}^{h}, L_{t}, D_{t+1}\right\}_{t=0}^{\infty}} E_{0} \sum_{t=0}^{\infty} \beta^{t}\left[\ln \left(C_{t}\right)+\zeta_{t} \ln \left(H_{t}^{h}\right)+\xi \ln \left(1-L_{t}\right)\right] \\
\text { subject to } C_{t}+Q_{t}^{h}\left[H_{t+1}^{h}-\left(1-\delta^{h}\right) H_{t}^{h}\right]=W_{t} L_{t}+R_{t} D_{t}-D_{t+1},
\end{gathered}
$$

where $C_{t}$ is consumption, $H_{t}^{h}$ is housing (residential real estate) stock in period $t, L_{t}$ is hours worked, $D_{t}$ is deposit held at financial intermediaries (made at time $t-1$ ), $W_{t}$ is the real wage rate, $Q_{t}^{h}$ is house price, and $R_{t}$ is the risk-free real interest rate from $t-1$ to $t$, which is independent of period $t$ shocks. In (16) $\beta$ is the discount factor, while $\zeta$ and $\xi$ govern the relative importance of housing and leisure, respectively, in the utility function. Note that we allow $\zeta$ to be stochastic: $\zeta_{t}$ represents the shock to preference for housing in period $t$. This serves as a parsimonious way of generating shocks to house prices (see also Iacoviello, 2005). For simplicity, we assume that $\left\{\zeta_{t}\right\}$ follows a mean-reverting $A R(1)$ process:

$$
\ln \zeta_{t+1}-\ln \bar{\zeta}=\rho_{\zeta}\left(\ln \zeta_{t}-\ln \bar{\zeta}\right)+\varepsilon_{\zeta, t+1}
$$

where $\varepsilon_{\zeta, t+1} \sim N\left(0, \sigma_{\zeta}^{2}\right)$ and $\bar{\zeta}$ is the nonstochastic steady state value of $\zeta_{t}$. The first-order conditions can be easily derived,

$$
\begin{gathered}
\xi \frac{C_{t}}{1-L_{t}}=W_{t} \\
\frac{1}{C_{t}}=\beta\left(E_{t} \frac{1}{C_{t+1}}\right) R_{t+1} \\
\frac{1}{C_{t}} Q_{t}^{h}=\beta E_{t}\left\{\frac{1}{C_{t+1}}\left[\frac{\zeta_{t+1} C_{t+1}}{H_{t+1}^{h}}+Q_{t+1}^{h}\left(1-\delta^{h}\right)\right]\right\} .
\end{gathered}
$$


Equation (19) is the labor supply condition, (20) is the conventional consumption-saving Euler equation, while (21) is the Euler equation pertaining to the accumulation of residential real estate.

\subsection{The Equilibrium System}

Having described the major players in the model economy, we now follow BGG in "closing our model" by grouping the equilibrium conditions into three major blocks: "aggregate demand," "aggregate supply," and the evolution of state variables.

\section{(1) Aggregate Demand}

The aggregate demand block consists of the entrepreneurial demand for assets (15), the division of entrepreneurial assets between capital and productive real estate (6), the aggregate rate of return on assets (7), the household consumption-saving Euler equation (20), the household's first-order condition for housing, (21), as well as the following conditions:

$$
\begin{gathered}
Y_{t}=C_{t}+I_{t}^{k}+I_{t}^{h}+C_{t}^{e}+\mu \int_{0}^{\bar{\omega}_{t}} \omega R_{t}^{a} M_{t} d F(\omega), \\
C_{t}^{e}=(1-\gamma) V_{t} \\
Q_{t}^{k}=\left[\Phi^{k \prime}\left(\frac{I_{t}^{k}}{K_{t}}\right)\right]^{-1}, \\
Q_{t}^{h}=\left[\Phi^{h \prime}\left(\frac{I_{t}^{h}}{H_{t}}\right)\right]^{-1}
\end{gathered}
$$

where

$$
V_{t} \equiv R_{t}^{k} M_{t}-\left[R_{t}+\frac{\mu \int_{0}^{\bar{\omega}_{t}} \omega R_{t}^{a} M_{t} d F(\omega)}{M_{t}-N_{t}}\right]\left(M_{t}-N_{t}\right) .
$$

Equation (22) is the aggregate resource constraint, where $I_{t}^{k}$ is aggregate investment in capital, $I_{t}^{h}$ is aggregate investment in real estate $\left(H_{t} \equiv H_{t}^{h}+H_{t}^{e}\right), C_{t}^{e}$ is aggregate 
entrepreneurial consumption. The last term represents bankruptcy costs. ${ }^{11}$ Equation (23) links aggregate entrepreneurial consumption to aggregate entrepreneurial equity which, as shown in (26), is the portion of total asset return left after creditors have been paid at the risk-free rate and are compensated for the bankruptcy cost. Equation (24) describes the price of capital. We follow BGG in assuming an adjustment-cost technology for producing capital. BGG show that this contributes to mimicking the investment behavior observed in the data. In particular, the amount of new capital produced per unit of existing capital is an increasing, concave function, represented by $\Phi^{k}(\cdot)$ of the investment-capital ratio. Hence the price of capital equals the marginal product of investment. Similarly, equation (25) is the price of real estate.

\section{(2) Aggregate Supply}

The aggregate supply block is composed of the aggregate production function (2) and the labor market equilibrium condition:

$$
\xi \frac{C_{t}}{1-L_{t}}=(1-\alpha) \frac{Y_{t}}{L_{t}}
$$

which is obtained from combining the household labor supply condition (19) and the entrepreneurs' optimality condition for labor demand.

\section{(3) Evolution of State Variables}

The evolutions of aggregate capital stock, real estate stock, and entrepreneurial net worth are

$$
\begin{aligned}
& K_{t+1}=\Phi^{k}\left(\frac{I_{t}^{k}}{K_{t}}\right) K_{t}+\left(1-\delta^{k}\right) K_{t} \\
& H_{t+1}=\Phi^{h}\left(\frac{I_{t}^{h}}{H_{t}}\right) H_{t}+\left(1-\delta^{h}\right) H_{t}
\end{aligned}
$$

\footnotetext{
${ }^{11}$ Note that, for simplicity, we have assumed that the rates of transformation between residential and entrepreneurial real estate are in unity.
} 


$$
\text { and } N_{t+1}=\gamma\left[R_{t}^{k} M_{t}-\left(R_{t}+\frac{\mu \int_{0}^{\bar{\omega}_{t}} \omega R_{t}^{k} M_{t} d F(\omega)}{M_{t}-N_{t}}\right)\left(M_{t}-N_{t}\right)\right],
$$

respectively. In equation (30) the term inside the brackets is simply aggregate entrepreneurial equity as defined in (26). ${ }^{12} 13$

Equations (15) and (30) constitute the building blocks of the so-called "financial accelerator." Increases in net worth leverage up increases in entrepreneurial assets, which in turn leads to further increases in entrepreneurial net worth in the future. Furthermore, equation (13) implies the countercyclicality of $E F P$, as procyclical asset prices and returns induce countercyclical default rate and monitoring costs.

\section{Quantitative Assessment}

\subsection{Calibration}

To understand the quantitative performance of the model, it is necessary to assign plausible parameter values. To facilitate the comparison, we follow BGG in assuming that the period used in the model corresponds to a quarter. On the household side, the parameter values are fairly standard. The preference parameters include $\beta, \bar{\zeta}$, and $\xi$, as in (16). $\beta$ is set at 0.99 to generate a steady state real interest rate of $4 \%$ per annum. The value of $\zeta$ is determined by the criterion that the steady state ratio of the value of house stock to GDP,

\footnotetext{
${ }^{12}$ For ease of presentation we have omitted entrepreneurial labor and wage income in the equilibrium system. BGG introduce these variables to make sure that entrepreneurs always have positive net worth. Quantitatively, they are negligible.

${ }^{13}$ Notice that the existence of adjustment cost in (28) means that the next period capital stock $K_{t+1}$ is likely to be less than the sum of aggregate investment $I_{t}^{k}$ and after-depreciation capital stock of the current period $\left(1-\delta^{k}\right) K_{t}$. For instance, if $\Phi^{k}()=.\frac{I_{t}^{k}}{K_{t}}$, i.e., a linear function, then by (28), we have $K_{t+1}$ $=\left(\frac{I_{t}^{k}}{K_{t}}\right) K_{t}+\left(1-\delta^{k}\right) K_{t}=I_{t}^{k}+\left(1-\delta^{k}\right) K_{t}$. However, if $\Phi^{k}()=.\left(\frac{I_{t}^{k}}{K_{t}}\right)^{2}$, i.e., a quadratic function, then by (28), we have $K_{t+1}=\left(\frac{I_{t}^{k}}{K_{t}}\right)^{2} K_{t}+\left(1-\delta^{k}\right) K_{t}=I_{t}^{k}\left(\frac{I_{t}^{k}}{K_{t}}\right)+\left(1-\delta^{k}\right) K_{t}$, which is less than $I_{t}^{k}+\left(1-\delta^{k}\right) K_{t}$, because the investment flow tends to be much smaller than the capital stock, $\left(\frac{I_{t}^{k}}{K_{t}}\right)<1$.
} 
$H^{h} / Y$, is equal to the corresponding average value in the data, which is roughly $1.11 .^{14}$ Following BGG, $\xi$ is such that the labor supply elasticity is 3 , which corresponds to a steady state value of 0.25 for labor supply (as a fraction of total time endowment).

On the production side, the share of labor, $(1-\alpha)$, is set at 0.65 . In terms of the share of the corporate real estate in the total assets, the estimates in the literature appear to be consistent with one another. For instance, Zeckhauser and Silverman (1983) find that on average real estate assets constitutes 25 to $40 \%$ of the total assets in the United States. In the sample analyzed by Veale (1989), the figure is around 25\%. Du et al. (2008) use more recent data and find that, on average, property accounts for $30 \%$ of a firm's physical assets. Accordingly, we set the share of real estate in relation to total entrepreneurial assets as equal to this number, implying $\phi=0.70$. In terms of the depreciation rates of capital and real estate, i.e., $\delta^{k}$ and $\delta^{h}$ in the model, we follow Jin and Zeng (2004) in setting them at $1.66 \%$ and $0.39 \%$, respectively, which correspond to annual rates of $6.48 \%$ and $1.54 \%$. There is no clear consensus in the literature about the value of the elasticity of the price of capital with respect to the investment capital ratio $\varphi^{k}$. BGG suggests that the value should lie within a range from 0 to 0.50 . We set $\varphi^{k}=0.50$. This value generates a standard deviation of capital investment to aggregate output of 2.29 and a relative standard deviation of capital price to aggregate output of 1.15 , both of which are close to their empirical values of 2.23 and 1.18 , respectively.

Regarding the entrepreneurial sector and the contract problem, we assume that the idiosyncratic risk, $\omega$, is distributed log-normally, i.e., $\ln \omega \sim N\left(-\frac{1}{2} \sigma^{2}, \sigma^{2}\right)$. Following

\footnotetext{
${ }^{14}$ To calculate this ratio, we use NIPA Table 2.1, "Current-Cost Net Stock of Private Fixed Assets, Equipment and Software, and Structures by Type", and Table 1.1.5, "Gross Domestic Product".
} 
BGG, we pin down $\sigma$, along with the bankruptcy parameter $\mu$ and the death rate of entrepreneurs $\gamma$, jointly using the following three criteria. (1) The steady state external finance premium $(E F P)$ equals the average spread between the prime lending rate and the 3-month T-bill rate, which is $2.62 \%$ per annum. (2) The quarterly bankruptcy rate equals 0.974\% (Fisher, 1999; Carlstrom and Fuerst, 1997). (3) The ratio of entrepreneurial assets to net worth equals 2 .

In the stochastic processes for productivity and house price shocks ((3) and (18)), the autocorrelation coefficients $\rho_{A}$ and $\rho_{\zeta}$ are set at 0.95 . The disturbances $\varepsilon_{A, t}$ and $\varepsilon_{\zeta, t}$ are assumed to be uncorrelated with each other. Their standard deviations $\sigma_{A}$ and $\sigma_{\zeta}$ are pinned down jointly with the elasticity of the price of real estate with respect to the corresponding investment flow-stock ratio $\varphi^{h}$ to match a standard deviation of aggregate output of $1.70 \%$, a relative standard deviation of house investment to aggregate output of 5.11, and a relative standard deviation of house price to aggregate output of 1.51 . It

turns out that $\varphi^{h}$ equals 0.30 , a much smaller value than $\varphi^{k}$, implying that real estate investment is subject to less severe adjustment costs than investment in physical capital, which is consistent with the fact that real estate investment is more volatile than capital investment over the business cycle.

\subsection{Results}

This section presents the results. Table $2 a$ reports the business cycle properties of the log-linearized version of our model. The column labeled "Data" lists the empirical values of the second moments we are interested in. The model's performance with regard to both 
of the sources of shock-, i.e. productivity and house price shocks - at work is described in the "Both shocks" column. It appears that the model matches the data very well in terms of the volatilities of capital investment, real estate investment, and the prices of capital and real estate. The contemporaneous correlations between these variables and aggregate output, except for the price of capital, are roughly in line with the data. In particular, real estate investment is less procyclical than capital investment, both in the data and in the model. Our primary interest is the behavior of the external finance premium. It turns out that the relative standard deviation of the EFP is 0.31 in the data and 0.26 in our model. Hence, the model explains approximately $84 \%$ of the $E F P$ volatility, given that the asset prices in our model exhibit similar volatilities to that found in the data. Consistent with the data, the EFP appears to be moderately countercyclical in our model $(-0.43$ in the data and -0.63 in our model).

As can be seen from Table 2a, the most visible inconsistency between the model and the data is that the actual price of capital is almost acyclic as a business cycle fact, while it appears strongly procyclical in the model. ${ }^{15}$ The strong procyclicality of the price of capital is an important feature of the BGG model. This inconsistency highlights the difficulty of relying on procyclical capital price to generate countercyclical EFP, as BGG did. ${ }^{16}$

On the other hand, our model captures the moderate procyclicality of house prices (the correlation between house prices and the GDP is 0.49 in the data and 0.67 in our model). Thus, the countercyclicality of the EFP and the procyclicality of house prices are

\footnotetext{
${ }^{15}$ Data on the price of capital are from "Net Stock Estimates of Fixed Reproducible Tangible Wealth" published by Bureau of Economic Analysis.

${ }^{16} \mathrm{We}$ do not attempt to reproduce the acyclicity of the price of capital. It is apparently difficult to do so within the adjustment-cost framework, which has become a workhorse in the business cycle literature. We attempt to address this in the future research.
} 
both replicated successfully by our model.

[Insert Table $2 a$ here.]

To gain a better understanding of how different shocks drive the model, the third and fourth columns of Table $2 a$ presents the performance of the model when only one shock is operating. When the model is subject solely to the productivity shock, only $55 \%$ of the EFP volatility can be explained. This is due mainly to the substantial drop in house price volatility (by 44\%) as compared to the both-shock case. The relative volatilities of capital investment and prices are only slightly less. However, the relative volatility of real estate investment is substantially smaller (2.78 versus 5.11 , which is the value in the data). On the other hand, when we compare the case of the housing demand shock (the last column of the upper section of Table 1) with the data (the first column of the upper section of Table 1), we find that the volatility of the EFP, the price of capital goods and real estate, and the investment in capital goods and real estate, are all significantly over-predicted. This appears to confirm the importance of including productivity shocks in the model.

The model successfully replicates the countercyclicality of the $E F P$, albeit in a stronger manner. The model with both shocks also slightly over-predicts the cyclicality of real estate prices and real estate investment. Had the model been driven by only one shock, the lower section of Table $2 a$ (the third and fourth columns) clearly shows that the counter-cyclicality of the EFP, and the cyclicality of real estate prices, and real estate investment would all be significantly exaggerated. Thus, the approach of this model, which is to incorporate both 
technology shocks and house demand shocks appear to be able to capable of capturing the behavior of the EFP and the real estate market better then some alternative models.

Table $2 a$ provides a summary of the dynamics of the major economic variables when the system is subject to continuous shocks, described by (3) and (18). We now provide a visualization of the short run dynamics of the model. Figure $3 a$ shows the impulse responses to a temporary productivity shock, with a magnitude of one standard deviation (the shock hits the system at period 5). Aggregate output, prices and investment in real estate and capital all go up in response to the shock, and interestingly exhibit a hump-shaped pattern. In contrast, the external finance premium goes down, signifying its countercyclicality. Figure $3 b$ presents the impulse responses to a temporary, one standard deviation house demand shock, which induces positive responses in aggregate output, prices and investment in real estate and capital, together with a negative response in the $E F P$. These impulse responses are broadly consistent with the intuition and the "stylized facts" identified by the VAR in an earlier section.

[Insert Figure $3 a, 3 b$ here.]

An important message conveyed by these results is that fluctuation of real estate prices is a more important influence on the cyclical fluctuation of the external finance premium than productivity shocks, although the latter is the major driving force considered in the standard dynamic stochastic general equilibrium business cycle models. Moreover, house price shock is also indispensable for explaining the observed mirror-image relation between 
the cyclicality of house prices and the EFP. In other words, successfully explaining the business cycle properties of the EFP hinges to a large extent on replicating the observed business cycle properties of house prices. The literature has highlighted the importance of house price fluctuations in inducing wealth effects on consumption and collateral effects on consumption and investment spending. ${ }^{17}$ In this paper, the wealth effect on consumption is embedded in the representative household problem, as she owns the residential real estate. To complement the literature, this paper focuses on the collateral effect on the production side rather than that on the household side. In addition, our paper adds a new twist into the literature, namely the impact of house price movements on the behavior of the external finance premium (EFP), and provides an additional propagation mechanism through the fluctuations of the EFP.

\subsection{The Role of Real Estate Price}

This section provides further diagnosis of the role real estate prices play in explaining the volatility of the EFP. First, we attempt to decompose the EFP into different components. From (10) we have $Z_{t}=\bar{\omega}_{t} R_{t}^{a} m_{t} /\left(m_{t}-1\right)$ where $m_{t} \equiv M_{t} / N_{t}$. However, the first-order conditions for the problem (14)-(13) give rise to the function $\bar{\omega}_{t}=f\left(R_{t}^{a} / R_{t}, m_{t}\right)$ (see Appendix B). Yet the equation (15) implies $m_{t+1}=\psi\left(E_{t}\left(R_{t+1}^{a} / R_{t+1}\right)\right)$. Putting all these together, we have

$$
\frac{Z_{t}}{R_{t}}=f\left(\frac{R_{t}^{a}}{R_{t}}, \psi\left(E_{t-1}\left(\frac{R_{t}^{a}}{R_{t}}\right)\right)\right) \frac{R_{t}^{a}}{R_{t}} \frac{\psi\left(E_{t-1}\left(\frac{R_{t}^{a}}{R_{t}}\right)\right)}{\psi\left(E_{t-1}\left(\frac{R_{t}^{a}}{R_{t}}\right)\right)-1} .
$$

\footnotetext{
${ }^{17}$ Among others, see Case et al. (2005) for the wealth effect, and Iacoviello (2005), Chen and Leung (2008) for the collateral effect.
} 
We therefore arrive at the following proposition: Given the stochastic process for the riskfree rate $R_{t}$, the stochastic process for the aggregate return on asset $R_{t}^{a}$ is a sufficient statistic for determining the external finance premium (represented as a fraction of the risk-free rate). This proposition implies that one needs only look at the behavior of $R_{t}^{a}$ to characterize the behavior of $E F P_{t}$, given that the volatility of $R_{t}$ is small compared to the volatility of $R_{t}^{a}$. In fact, the procyclicality of $R_{t}^{a}$ is responsible for the countercyclicality of $E F P_{t}$. Loglinearizing equation (7), the equation that implicitly determines $R_{t}^{a}$, and using a hat to denote log deviation from the steady state yields

$\hat{R}_{t}^{a}=\theta_{1}\left[\hat{Y}_{t}-\phi \hat{K}_{t}-(1-\phi) \hat{H}_{t}^{e}\right]+\theta_{2}\left[\left(1-\delta^{k}\right) \hat{Q}_{t}^{k}-R^{a} \hat{Q}_{t-1}^{k}\right]+\theta_{3}\left[\left(1-\delta^{h}\right) \hat{Q}_{t}^{h}-R^{a} \hat{Q}_{t-1}^{h}\right]$

where

$$
\begin{aligned}
& \theta_{1}=\left[\frac{\phi Q^{k}}{R^{a} Q^{k}-\left(1-\delta^{k}\right) Q^{k}}+\frac{(1-\phi) Q^{h}}{R^{a} Q^{h}-\left(1-\delta^{h}\right) Q^{h}}\right]^{-1}\left(R^{a}\right)^{-1} \\
& \theta_{2}=\theta_{1} \frac{\phi Q^{k}}{R^{a} Q^{k}-\left(1-\delta^{k}\right) Q^{k}} \\
& \theta_{3}=\theta_{1} \frac{(1-\phi) Q^{h}}{R^{a} Q^{h}-\left(1-\delta^{h}\right) Q^{h}}
\end{aligned}
$$

Hence we have decomposed the log deviation of the aggregate return on assets into three components: (1) the log deviation of the marginal product of entrepreneurial asset, viewed as a composite of capital and real estate, (2) the term involving the price of capital, and (3) the term involving the price of real estate.

Table $2 b$ presents the decomposition of the volatility of $R_{t}^{a}$ according to (32). It is apparent that the marginal product term contributes little to the volatility of the aggregate return on assets. With productivity shocks and house price shocks both operational, the 
contribution made by house price fluctuations is around $75 \%$ of the contribution from capital price fluctuations, amounting to roughly $44 \%$ of the total volatility of the aggregate return on assets. The relative contribution of house price fluctuations is especially large when the economy is hit by a house price shock, as house prices exhibit greater volatility than capital prices. In sum, these results show that, quantitatively, house price fluctuations are important sources of fluctuations in the aggregate return on assets, and are thus important factors in accounting for the volatility of the external finance premium.

[Insert Table $2 b$ here.]

\subsection{Robustness}

Clearly, any quantitative result of a dynamic stochastic general equilibrium model depends on the values assigned to its parameters. In this session, we examine the changes in the model's performance under alternative parameter values. Because the EFP is an important aspect of this paper and other parameter values have been studied in the previous literature, this section will focus on the key parameters capable of affecting financial contracts, namely, the monitoring cost parameter $\mu$ and the dispersion parameter $\sigma$ for entrepreneurial idiosyncratic risk. The monitoring cost parameter, $\mu$, is intended to capture costs associated with bankruptcy, the value of which appears to be controversial in the literature. Warner (1977) examines the railroad industry and estimates the cost of bankruptcy to be about 4 percent. This estimate, however, does not include the direct costs of financial distress, such as lost revenues and profits. Altman (1984) estimates the 
sum of direct and indirect bankruptcy costs to be about 20 percent of firms' total assets. Another measure of bankruptcy costs is obtained by Alderson and Betker (1995) by comparing the value of a firm as a going concern with its liquidation value. They calculate that liquidation costs are, on average, equal to approximately 36 percent of a firm's assets. The value we take for $\mu$ in our benchmark simulation (described in the previous subsection) is 0.59 , which matches the average spread between the prime lending rate and the 3 -month T-bill rate $(2.62 \%$ per annum). This value is clearly larger than the direct estimates suggested in the literature. However, when we match the model's steady state EFP with the historical average of the spread between the prime lending rate and the 3 -month commercial paper rate $(1.90 \%$ per annum), the value for $\mu$ turns out to be 0.40 , which is close to the estimate of Alderson and Betker.

Table 3 compares the model's performance under different values for the monitoring cost parameter $\mu$, holding all other parameter values unchanged. It is clear that lower values of $\mu$, and hence lower steady state values of $E F P$, are associated with lower $E F P$ volatilities. When $\mu=0.40$, the relative standard deviation of the EFP drops to $68 \%$ of the empirical value. When $\mu$ takes the value (0.20) reported by Altman (1984), the relative EFP volatility further drops to $45 \%$ of the empirical value. However, that fluctuations in real estate prices contribute more than fluctuations in capital prices to the volatility of the aggregate return on assets, and hence the external finance premium, is a robust feature of our model. In fact, the relative contribution from real estate price fluctuations increases with smaller value of $\mu$. The other features of our model that remain robust include: first, that the EFP is moderately countercyclical and, second, that compared to productivity shocks, house demand shocks induce larger relative volatilities in the $E F P$, 
and larger relative contributions to $E F P$ volatility from fluctuations in real estate prices.

[Insert Table 3 here.]

Next, we look at the effects of varying the dispersion parameter $\sigma$ for entrepreneurial idiosyncratic risk while holding all other parameters fixed at their benchmark values, the results of which are listed in Table 4. A larger dispersions of entrepreneurial idiosyncratic risk is associated with larger relative volatility of the EFP. When $\sigma=0.50$, the model exactly replicates the relative standard deviation in the data. ${ }^{18}$ It appears that the magnified effect of house price shocks, rather than productivity shocks, is the reason for this. The contribution from real estate price fluctuations, relative to capital price fluctuations, does not change much with variations in $\sigma$. Finally, the moderate countercyclicality of the EFP remains a robust feature of the model. Overall, the principal conclusions of this paper appear to be robust to alternative parameter values.

[Insert Table 4 here.]

\section{Conclusions}

This paper attempts to marry two different literatures relating to aggregate economic activities. The first reflects the increasing awareness that the housing market plays an

\footnotetext{
${ }^{18} \mathrm{~A}$ value of 0.50 for $\sigma$ corresponds to a steady state value for $E F P$ of $4.04 \%$ per annum, an asset-net worth ratio of 1.44 , and a quarterly bankruptcy rate of $1.45 \%$.
} 
important role in the aggregate economy, with the wealth effect of consumption, and the collateral effect on the household side being highlighted recently. ${ }^{19}$ The second concerns how the imperfect capital market may affect the aggregate economy. ${ }^{20}$ This paper begins with an empirical observation that a positive real house price shock indeed lowers the external finance premium and stimulates nonresidential investment and a real increase in GDP (see the impulse response in Figure 1). The paper then proceeds to introduce residential and corporate real estate into the BGG model, which is regarded as a standard vehicle for bringing the imperfect capital market into business cycle analysis. The quantitative theoretical model is calibrated to match certain observed features of the U.S. aggregate economy, including the relative volatility of the external finance premium, the relative price of housing and capital, as well as the levels of investment in real estate and capital. Interestingly, the stylized model captures the moderate counter-cyclicality of the external finance premium and the moderate cyclicality of house prices. Further analysis shows that the fluctuations in real estate prices account for nearly half of the volatility of the aggregate return on assets, which in turn significantly drives the movement of the external finance premium. The robustness checks also confirm that house demand shocks and house prices fluctuations indeed account for an important share of the volatility of the aggregate output.

Clearly, future research can extend in many directions. First, more careful empirical studies of the relationship between the credit market and the real estate market, and their influence on aggregate output are needed. Second, the model presented in this paper is

\footnotetext{
${ }^{19}$ Among others, see Leung (2004), Leung and Quigley (2007) for a review of the literature.

${ }^{20}$ Again, see BGG for a review of that literature.
} 
very stylized and can be extended to include other important features, including nominal rigidities, government spending and tax, as well as monetary policy. ${ }^{21}$ In addition, the real estate market is presented in a highly simplified manner and can be extended to incorporate other realistic aspects of the market, such as securitization. Efforts are currently underway in these research directions.

\section{Acknowledgement:}

The authors are grateful to (alphabetical order) the comments and suggestions from Man Cho, Angus Chu, Christopher Hennessy, Nobuhiro Kiyotaki, Walter Torous, an anonymous referee, the seminar participants of Academia Sinica (Taiwan), AREUEA meeting, Bank of Japan, City University of Hong Kong, Koc University, National Taiwan University, Taiwan Economic Association meeting, World Congress of the Econometric Society meeting (Shanghai) and an anonymous referee for comments and discussion and Lichao Cheng for excellent research assistance. The work described in this paper was partially supported by a grant from the Research Grants Council of the Hong Kong Special Administrative Region, China [Project No. CityU 144709]. The usual disclaimer applies.

\footnotetext{
${ }^{21}$ Among others, see Chen and Leung (2008), Chen, Cheng and Mao (2010) for earlier efforts on these lines.
} 


\section{References}

[1] Alderson, M. J. and B. L. Betker. 2001. Liquidation costs and capital structure. Empirical Corporate Finance 3: 92-116.

[2] Almeida, H., M. Campello and C. Liu. 2006. The Financial Accelerator: Evidence from International Housing Markets. Review of Finance 10: 1-32.

[3] Altman, E. I. 1984. A further investigation of the bankruptcy cost question. Journal of Finance 39(4): 1067-1089.

[4] Andrew, M. and G. Meen. 2003. House Price Appreciation, Transactions and Structural Change in the British Housing Market: A Macroeconomic Perspective. Real Estate Economics 31(1): 99-117.

[5] Bernanke, B. and M. Gertler. 1995. Inside the Black Box: The Credit Channel of Monetary Policy Transmission. Journal of Economic Perspectives 9(4): 27-48.

[6] Bernanke, B., M. Gertler and S. Gilchrist. 1999. The Financial Accelerator in A Quantitative Business Cycle Framework, in J. Taylor and M. Woodford ed. Handbook of Macroeconomics Vol. 1, New York: Elsevier.

[7] Boyd, J. H. and B. Smith. 1997. Capital Market Imperfections, International Credit Markets, and Nonconvergence. Journal of Economic Theory 73: 335-64.

[8] Brown, D.; B. Ciochetti and T. Riddiough. 2006. Theory and Evidence on the Resolution of Financial Distress Review of Financial Studies 19: 1357-1397.

[9] Burnside, C.; M. Eichenbaum and S. Rebelo. 1995. Capital utilization and returns to scale. NBER Macroeconomics Annual 67-100.

[10] Capozza, D.; P. Hendershott and C. Mack. 2004. An Anatomy of Price Dynamics in Illiquid Markets: Analysis and Evidence from Local Housing Markets. Real Estate Economics 32(1): 1-32.

[11] Carlstrom, C. and T. Fuerst. 1997. Agency Costs, Net Worth, and Business Fluctuations: A Computable General Equilibrium Analysis. American Economic Review 87: 893-910.

[12] Case, K.; J. Quigley and R. Shiller. 2005. Comparing wealth effects: the stock market versus the housing market. Advances in Macroeconomics 5(1), article 1. http://www.bepress.com/bejm/advances/vol5/iss1/art1.

[13] Chang, K. L.; N. K. Chen and C. K. Y. Leung. 2010. Would some model please give me some hints? In search of some stylized facts of the Monetary Policy and Asset Return Dynamics, City University of Hong Kong, mimeo. 
[14] Chen, N. K.; H. L. Cheng and C. S. Mao. 2010. External Finance Premium on Housing, House Price, and the Macroeconomy, National University of Taiwan, mimeo.

[15] Chen, N. K. and C. K. Y. Leung. 2008. Asset Price Spillover, Collateral and Crises: with an Application to Property Market Policy. Journal of Real Estate Finance and Economics 37: 351-385.

[16] Christiano, L. J., M. Eichenbaum, and C. L. Evans. 1999. Monetary Policy Shocks: What Have We Learned and to What End?. in J. Taylor and M. Woodford ed. Handbook of Macroeconomics Vol. 1, New York: Elsevier.

[17] Clapp, J. M.; W. Dolde and D. Tirtiroglu. 1995. Imperfect Information and Investor Inferences From Housing Price Dynamics. Real Estate Economics 23(3): 239-269.

[18] Clayton, J. 1996. Rational Expectations, Market Fundamentals and Housing Price Volatility. Real Estate Economics 24(4): 441-470.

[19] Del Negro, M.; C. Otrok. 2007. 99 Luftballons: Monetary Policy and the House Price Boom across U.S. States. Journal of Monetary Economics 54: 1962-85.

[20] Dong, Y.; C. K. Y. Leung and D. Cai. 2010. What Drives Fixed Asset Holding and its Investment Efficiency in China? A firm level analysis. City University of Hong Kong, mimeo.

[21] Du, J.; C. K. Y. Leung, and D. K. H. Chu. 2008. Return enhancing, cash-rich, or simply empire building? An empirical investigation of corporate real estate holdings. City University of Hong Kong, mimeo.

[22] Espen Eckbo, B. and S. K. Thorburn. 2008. Automatic Bankruptcy Auctions and Fire-Sales. Journal of Financial Economics 89: 404-22.

[23] Fisher, J. 1999. Credit Market Imperfection and the Heterogeneous Response of Firms to Monetary Shocks. Journal of Money, Credit and Banking 31: 187-211.

[24] Gale, D. and M. Hellwig. 1985. Incentive Compatible Debt Contracts I: The One Period Problem. Review of Economic Studies 52: 647-664.

[25] Gallin. J. 2006. The Long-Run Relationship between House Prices and Income: Evidence from Local Housing Markets. Real Estate Economics 34(3): 417-439.

[26] Greenwood, J. and Z. Hercowitz. 1991. The allocation of capital and time over the business cycle. Journal of Political Economy 99: 1188-1214.

[27] Huybens, E. and B. Smith. 1998. Financial Market Frictions, Monetary Policy, and Capital Accumulation in a Small Open Economy. Journal of Economic Theory 81: 353-400. 
[28] Iacoviello, M. 2005. House Prices, borrowing constraints and monetary policy in the business cycle. American Economic Review 95(3): 739-764.

[29] Iacoviello, M. and R. Minetti. 2003. Financial liberalization and the sensitivity of house prices to monetary policy: theory and evidence. Manchester School 71: 20-34.

[30] Iacoviello, M. and R. Minetti. 2008. The Credit Channel of Monetary Policy: Evidence from the Housing Market. Journal of Macroeconomics 30: 69-96.

[31] Jin, Y. and Z. Zeng. 2004. Residential investment and house prices in a multi-sector monetary business cycle model. Journal of Housing Economics 13: 268-286.

[32] Leung, C. K. Y. 2004. Macroeconomics and Housing: a review of the literature. Journal of Housing Economics 13: 249-267.

[33] Leung, C. K. Y. and J. Quigley. 2007. Special issue on macroeconomics, regulation, and housing introduction. Journal of Housing Economics 16: 99-101.

[34] Liow, K. H. 1995. Property in corporate financial statements: the U.K. Evidence. Journal of Property Research 12: 13-28.

[35] Lustig, H. N.; S. van Nieuwerburgh. 2005. Housing Collateral, Consumption Insurance, and Risk Premia: An Empirical Perspective. Journal of Finance 60: 1167-1219.

[36] Manove, M.; A. J. Padilla and M. Pagano. 2001. Collateral versus project screening: a model of lazy banks. RAND Journal of Economics 32(4): 726-744.

[37] Mookherjee, D. and I. Png. 1989. Optimal auditing insurance, and redistribution. Quarterly Journal of Economics 104: 399-415.

[38] Muellbauer, J.; A. Murphy. 1997. Booms and Busts in the UK Housing Market. Economic Journal 107: 1701-27.

[39] Shleifer, A. and R. Vishny. 1992. Liquidation Values and Debt Capacity: A Market Equilibrium Approach. Journal of Finance 47: 1343-66.

[40] Sims, C. 1980. Macroeconomics and reality. Econometrica, 48: 1-48.

[41] Smith, B. and C. Wang. 1998. Repeated Insurance Relationships in a Costly State Verification Model: With an Application to Deposit Insurance. Journal of Monetary Economics 42: 207-40.

[42] Townsend, R. 1979. Optimal Contracts and Competitive Markets with Costly State Verification. Journal of Economic Theory 21: 265-93.

[43] Veale, P. 1989. Managing corporate real estate assets: current executive attitudes and prospects for emergent management discipline. Journal of Real Estate Research 22: $1-22$. 
[44] Wang, K., L. Young, and Y. Zhou. 2002. Nondiscriminating Foreclosure and Voluntary Liquidating Costs. Review of Financial Studies 15: 959-985.

[45] Warner, J. 1977. Bankruptcy costs: some evidence. Journal of Finance 32(2): 337348.

[46] Williamson, S. 1986. Costly Monitoring, Financial Intermediation and Equilibrium Credit Rationing. Journal of Monetary Economics 18: 159-179.

[47] Williamson, S. 1987. Financial Intermediation, Business Failures, and Real Business Cycles. Journal of Political Economy 95: 1196-1216.

[48] Zeckhauser, S. and R. Silverman. 1983. Rediscover your company's real estate. Harvard Business Review 61: 111-117. 
Table 1. Sequence of Events Relevant to Entrepreneurs with Period $t$

\begin{tabular}{ll}
\hline \hline 1. & Begin period $t$ \\
2. & Death and birth of entrepreneurs \\
3. & Aggregate shocks realize \\
4. & Idiosyncratic shocks realize \\
5. & Production using labor, capital $K_{t}$, and real estate $H_{t}^{e}$ \\
6. & Repayment on previous debt $B_{t}$ or bankruptcy \\
7. & Contract: borrowing $B_{t+1}+$ net worth $N_{t+1} \Longrightarrow$ total asset value $M_{t+1}$ \\
8. & Purchase of capital $K_{t+1}$ and real estate $H_{t+1}^{e}$ using $M_{t+1}$ \\
9. & Move to period $t+1$ \\
\hline \hline
\end{tabular}


Table 2a. Business cycle properties of the model

\begin{tabular}{|c|c|c|c|c|}
\hline \multicolumn{5}{|c|}{ Relative volatilities to real GDP } \\
\hline & Data & Both shocks & Productivity shock & House Demand shock \\
\hline$E F P$ & 0.31 & $0.26(0.03)$ & $0.17(0.01)$ & $0.76(0.01)$ \\
\hline$Q^{h}$ & 1.51 & $1.51(0.15)$ & $0.84(0.00)$ & $4.98(0.07)$ \\
\hline$Q^{k}$ & 1.18 & $1.15(0.04)$ & $1.05(0.00)$ & $2.06(0.02)$ \\
\hline$I^{h}$ & 5.11 & $5.11(0.51)$ & $2.78(0.01)$ & $16.56(0.23)$ \\
\hline$I^{k}$ & 2.23 & $2.29(0.07)$ & $2.09(0.01)$ & $4.11(0.05)$ \\
\hline \multicolumn{5}{|c|}{ Correlations with real GDP } \\
\hline & Data & Both shocks & Productivity shock & House Demand shock \\
\hline$E F P$ & -0.43 & $-0.63(0.07)$ & $-0.74(0.01)$ & $-0.89(0.02)$ \\
\hline$Q^{h}$ & 0.49 & $0.67(0.08)$ & $1.00(0.00)$ & $0.78(0.04)$ \\
\hline$Q^{k}$ & 0.06 & $0.97(0.01)$ & $1.00(0.00)$ & $0.98(0.00)$ \\
\hline$I^{h}$ & 0.47 & $0.67(0.08)$ & $1.00(0.00)$ & $0.77(0.04)$ \\
\hline$I^{k}$ & 0.75 & $0.97(0.01)$ & $1.00(0.00)$ & $0.98(0.00)$ \\
\hline
\end{tabular}

Note: The relative volatility of the variable $x$ is $\operatorname{std}(x) / \operatorname{std}(Y)$. Y : real GDP, EFP: external finance premium, $Q^{h}$ : house price, $Q^{k}$ : price of capital, $I^{h}$ : investment in real estate, $I^{k}$ : investment in capital, $C$ : consumption. $Q^{h}, Q^{k}, I^{h}, I^{k}$, and $C$ are logged. EFP is in percent per annum. All series are HP-filtered with the smoothing parameter set to 1600. The statistics reported are means over 500 simulations with standard deviations in the parentheses. 
Table 2b. Decomposition of the volatility of the aggregate return to asset

\begin{tabular}{|l|ccc|}
\hline \hline & Both shocks & Productivity shock & House Demand shock \\
\hline Return to asset & 1.56 & 1.14 & 1.08 \\
Marginal product & 0.07 & 0.06 & 0.02 \\
Capital price & 0.91 & 0.78 & 0.48 \\
Real estate price & 0.68 & 0.33 & 0.61 \\
\hline \hline
\end{tabular}

Note: "Return to asset" refers to $\hat{R}_{t}^{a}$, "marginal product" refers to $\theta_{1}\left[\hat{Y}_{t}-\phi \hat{K}_{t}-(1-\phi) \hat{H}_{t}^{e}\right]$, "capital price" refers to $\theta_{2}\left[\left(1-\delta^{k}\right) \hat{Q}_{t}^{k}-R^{a} \hat{Q}_{t-1}^{k}\right]$, and "real estate price" refers to $\theta_{3} \times$ $\left[\left(1-\delta^{h}\right) \hat{Q}_{t}^{h}-R^{a} \hat{Q}_{t-1}^{h}\right]$ as in equation (32). All series are HP-filtered with the smoothing parameter set to 1600 before their standard deviations (expressed in percentage terms) are computed. The statistics reported are means over 500 simulations. The standard deviations over these simulations are all virtually zero and are thus not reported. 
Table 3. Sensitivity to the monitoring cost parameter

\begin{tabular}{|l|l|c|c|c|}
\hline \hline & & Both shocks & Productivity shock & House Demand shock \\
\hline Relative & $\mu=0.59$ & 0.26 & 0.17 & 0.76 \\
volatility & $\mu=0.40$ & 0.21 & 0.13 & 0.75 \\
of $E F P$ & $\mu=0.20$ & 0.14 & 0.09 & 0.79 \\
\hline Relative & $\mu=0.59$ & 0.75 & 0.42 & 1.27 \\
contribution & $\mu=0.40$ & 0.77 & 0.48 & 1.29 \\
from $Q^{h}$ & $\mu=0.20$ & 0.82 & 0.60 & 1.39 \\
\hline Correlation & $\mu=0.59$ & -0.63 & -0.74 & -0.89 \\
of $E F P$ & $\mu=0.40$ & -0.63 & -0.82 & -0.80 \\
with $Y$ & $\mu=0.20$ & -0.59 & -0.94 & -0.29 \\
\hline \hline
\end{tabular}

Note: Relative volatility of EFP refers to the standard deviation of EFP divided by the standard deviation of $Y$. Relative contribution from $Q^{h}$ refers to the standard deviation of the $\theta_{3}\left[\left(1-\delta^{h}\right) \hat{Q}_{t}^{h}-R^{a} \hat{Q}_{t-1}^{h}\right]$ term as in equation (32) divided by the standard deviation of the $\theta_{2}\left[\left(1-\delta^{k}\right) \hat{Q}_{t}^{k}-R^{a} \hat{Q}_{t-1}^{k}\right]$ term.

Table 4. Sensitivity to dispersion of entrepreneurial idiosyncractic risks

\begin{tabular}{|l|l|c|c|c|}
\hline \hline & & Both shocks & Productivity shock & House Demand shock \\
\hline Relative & $\sigma=0.50$ & 0.31 & 0.15 & 1.07 \\
volatility & $\sigma=0.29$ & 0.26 & 0.17 & 0.76 \\
of $E F P$ & $\sigma=0.10$ & 0.20 & 0.17 & 0.47 \\
\hline Relative & $\sigma=0.50$ & 0.82 & 0.46 & 1.15 \\
contribution & $\sigma=0.29$ & 0.75 & 0.42 & 1.27 \\
from $Q^{h}$ & $\sigma=0.10$ & 0.70 & 0.46 & 1.76 \\
\hline Correlation & $\sigma=0.50$ & -0.51 & -0.74 & -0.83 \\
of $E F P$ & $\sigma=0.29$ & -0.63 & -0.74 & -0.89 \\
with $Y$ & $\sigma=0.10$ & -0.73 & -0.76 & -0.85 \\
\hline \hline
\end{tabular}

Note: Relative volatility of EFP refers to the standard deviation of EFP divided by the standard deviation of $Y$. Relative contribution from $Q^{h}$ refers to the standard deviation of the $\theta_{3}\left[\left(1-\delta^{h}\right) \hat{Q}_{t}^{h}-R^{a} \hat{Q}_{t-1}^{h}\right]$ term as in equation (32) divided by the standard deviation of the $\theta_{2}\left[\left(1-\delta^{k}\right) \hat{Q}_{t}^{k}-R^{a} \hat{Q}_{t-1}^{k}\right]$ term. 


\section{Appendix}

\section{A. Derivation of the Aggregate Return on Asset ((6), (7))}

Consider the entrepreneur's asset division problem (4)-(5). Let $\tilde{R}_{t}^{a}$ be the Lagrangian multiplier on (5), which is also the expected return to capital from period $(t-1)$ to $t$. Then the first-order conditions with respect to $K_{t}^{j}$ and $H_{t}^{e j}$ are

$$
\begin{aligned}
E_{t-1}\left[\frac{\alpha Y_{t}}{\left(K_{t}\right)^{\phi}\left(H_{t}^{e}\right)^{1-\phi}} \phi\left(\frac{K^{j}}{H^{e j}}\right)^{\phi-1}+Q_{t}^{k}\left(1-\delta^{k}\right)\right] & =\tilde{R}_{t}^{a} Q_{t-1}^{k}, \\
E_{t-1}\left[\frac{\alpha Y_{t}}{\left(K_{t}\right)^{\phi}\left(H_{t}^{e}\right)^{1-\phi}}(1-\phi)\left(\frac{K^{j}}{H^{e j}}\right)^{\phi}+Q_{t}^{h}\left(1-\delta^{h}\right)\right] & =\tilde{R}_{t}^{a} Q_{t-1}^{h} .
\end{aligned}
$$

These two conditions can be rewritten as

$$
\begin{aligned}
E_{t-1}\left[\frac{\alpha Y_{t}}{\left(K_{t}\right)^{\phi}\left(H_{t}^{e}\right)^{1-\phi}} \phi\left(\frac{K^{j}}{H^{e j}}\right)^{\phi-1}+Q_{t}^{k}\left(1-\delta^{k}\right)\right] & =E_{t-1}\left(R_{t}^{a}\right) Q_{t-1}^{k}, \\
E_{t-1}\left[\frac{\alpha Y_{t}}{\left(K_{t}\right)^{\phi}\left(H_{t}^{e}\right)^{1-\phi}}(1-\phi)\left(\frac{K^{j}}{H^{e j}}\right)^{\phi}+Q_{t}^{h}\left(1-\delta^{h}\right)\right] & =E_{t-1}\left(R_{t}^{a}\right) Q_{t-1}^{h},
\end{aligned}
$$

where the realized return to capital, $R_{t}^{a}$, is defined by

$$
\begin{aligned}
\frac{\alpha Y_{t}}{\left(K_{t}\right)^{\phi}\left(H_{t}^{e}\right)^{1-\phi}} \phi\left(\frac{K^{j}}{H^{e j}}\right)^{\phi-1}+Q_{t}^{k}\left(1-\delta^{k}\right) & =R_{t}^{a} Q_{t-1}^{k}, \\
\frac{\alpha Y_{t}}{\left(K_{t}\right)^{\phi}\left(H_{t}^{e}\right)^{1-\phi}}(1-\phi)\left(\frac{K^{j}}{H^{e j}}\right)^{\phi}+Q_{t}^{h}\left(1-\delta^{h}\right) & =R_{t}^{a} Q_{t-1}^{h}
\end{aligned}
$$

which is (6). The interpretation of $R_{t}^{a}$ is what the entrepreneur would obtain on her capital if she were allowed to optimally divide $M_{t}^{j}$ between $K_{t}^{j}$ and $H_{t}^{e j}$ after observing the period $t$ aggregate shock (but before observing the idiosyncratic shock). The latter two equations imply that $R_{t}^{a}$ satisfies (7),

$$
\left[R_{t}^{a} Q_{t-1}^{k}-Q_{t}^{k}\left(1-\delta^{k}\right)\right]^{\phi}\left[R_{t}^{a} Q_{t-1}^{h}-Q_{t}^{h}\left(1-\delta^{h}\right)\right]^{(1-\phi)}=\phi^{\phi}(1-\phi)^{1-\phi} \frac{\alpha Y_{t}}{\left(K_{t}\right)^{\phi}\left(H_{t}^{e}\right)^{1-\phi}} .
$$

Apparently $R_{t}^{a}$ is independent of individual entrepreneurs' characteristics.

\section{B. Solution to the Optimal Contract Problem}

Let

$$
m_{t+1} \equiv \frac{M_{t+1}}{N_{t+1}}, \quad s_{t} \equiv \frac{E_{t}\left(R_{t+1}^{a}\right)}{R_{t+1}}, \quad \widetilde{u}_{t+1} \equiv \frac{R_{t+1}^{a}}{E_{t}\left(R_{t+1}^{a}\right)},
$$


and

$$
\Upsilon\left(\bar{\omega}_{t+1}\right) \equiv 1-\Gamma\left(\bar{\omega}_{t+1}\right)+\lambda_{t+1}\left[\Gamma\left(\bar{\omega}_{t+1}\right)-\mu G\left(\bar{\omega}_{t+1}\right)\right]
$$

where $\lambda_{t+1}$ is the Lagrangian multiplier on (13), one for each realization of $R_{t+1}^{a}$. The first-order conditions for problem (14)-(13) are then

$$
\begin{aligned}
\bar{\omega}_{t+1}: & \Gamma^{\prime}\left(\bar{\omega}_{t+1}\right)-\lambda_{t+1}\left[\Gamma^{\prime}\left(\bar{\omega}_{t+1}\right)-\mu G^{\prime}\left(\bar{\omega}_{t+1}\right)\right]=0 \\
m_{t+1}: & E\left[\Upsilon\left(\bar{\omega}_{t+1}\right) \widetilde{u}_{t+1} s_{t}-\lambda_{t+1}\right]=0 \\
\lambda_{t+1} & :\left[\Gamma\left(\bar{\omega}_{t+1}\right)-\mu G\left(\bar{\omega}_{t+1}\right)\right] \widetilde{u}_{t+1} s_{t} m_{t+1}-\left(m_{t+1}-1\right)=0 .
\end{aligned}
$$

The first-order condition with respect to $\bar{\omega}_{t+1}$ defines a function $\lambda\left(\bar{\omega}_{t+1}\right)$, with $\lambda^{\prime}\left(\bar{\omega}_{t+1}\right)>$ 0 . Then the first-order condition with respect to $\lambda_{t+1}$ implicitly defines a function $\bar{\omega}_{t+1}=$ $\bar{\omega}\left(\widetilde{u}_{t+1}, s_{t}, m_{t+1}\right)$, with $\partial \bar{\omega}_{t+1} / \partial s_{t}<0$ and $\partial \bar{\omega}_{t+1} / \partial m_{t+1}>0$. Substituting the first and third first-order conditions into the first-order condition for $m_{t+1}$, we have

$$
E\left\{\Upsilon\left(\bar{\omega}\left(\widetilde{u}_{t+1}, s_{t}, m_{t+1}\right)\right) \widetilde{u}_{t+1} s_{t}-\lambda\left(\bar{\omega}\left(\widetilde{u}_{t+1}, s_{t}, m_{t+1}\right)\right)\right\}=0
$$

This equation implicitly defines the function $m_{t+1}=\psi\left(s_{t}\right), \psi^{\prime}\left(s_{t}\right)>0, \psi(1)=1$. 


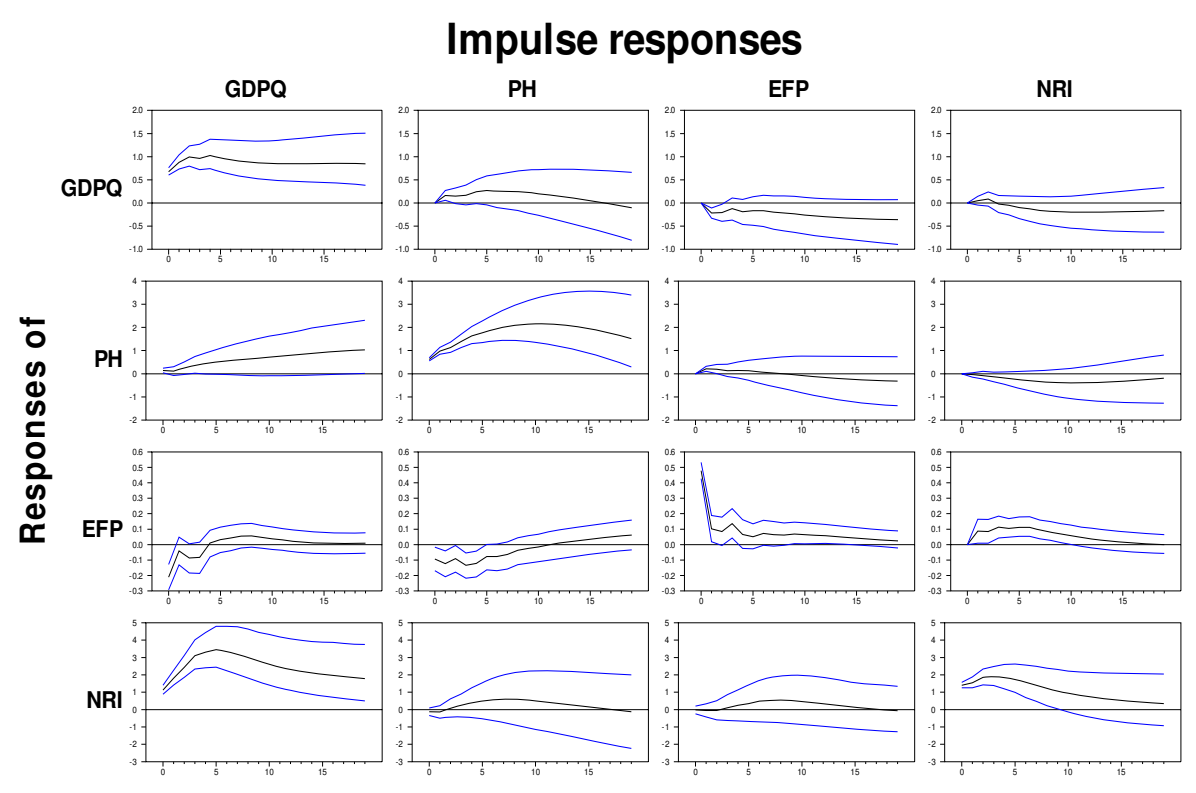

Figure 1. VAR impulse responses

Note: $G D P Q$ refers to the $\log$ of real GDP, $P H$ refers to $\log$ real OFHEO house price (deflated by implicit price deflator for personal consumption expenditure), EFP refers to the extent finance premium which is the spread between the prime lending rate and the 3-month T-bill rate, and NRI refers to log real nonresidential investment. The sample period is 1975Q1-2008Q2. The number of lags, which equals four, is determined by Akaike Information Criterion (AIC) and Schwarz Information Criterion (SIC). The plots are in terms of percentage deviations. The confidence bands are computed by Monte Carlo method (5000 draws). The blue lines represent $90 \%$ confidence intervals. The first column presents responses to GDPQ shock, the second $P H$ shock, the third $E F P$ shock, and the forth $N R I$ shock. 


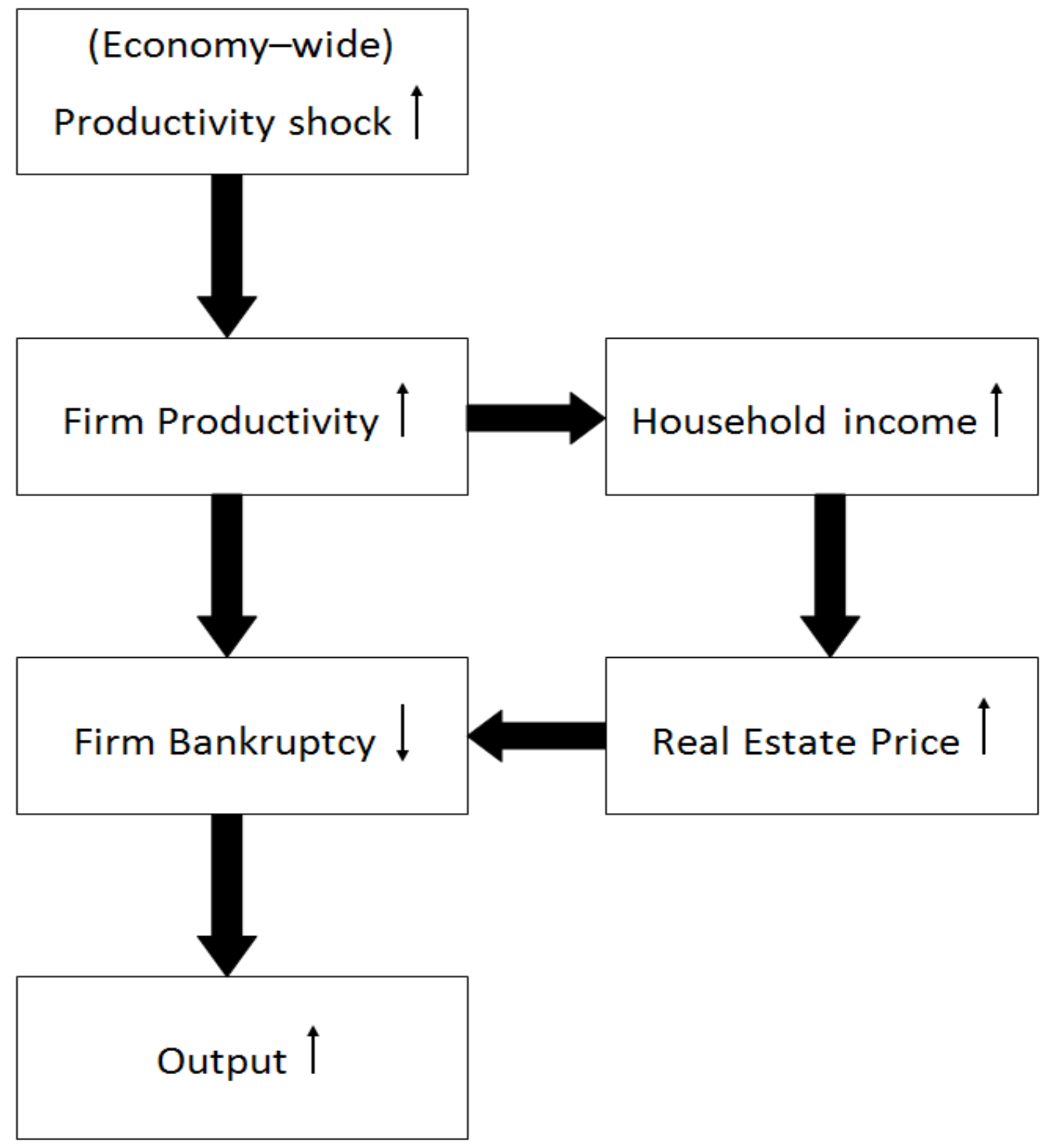

Figure 2: An illustration on how the real estate market, imperfect capital market and the aggregate output are related. 

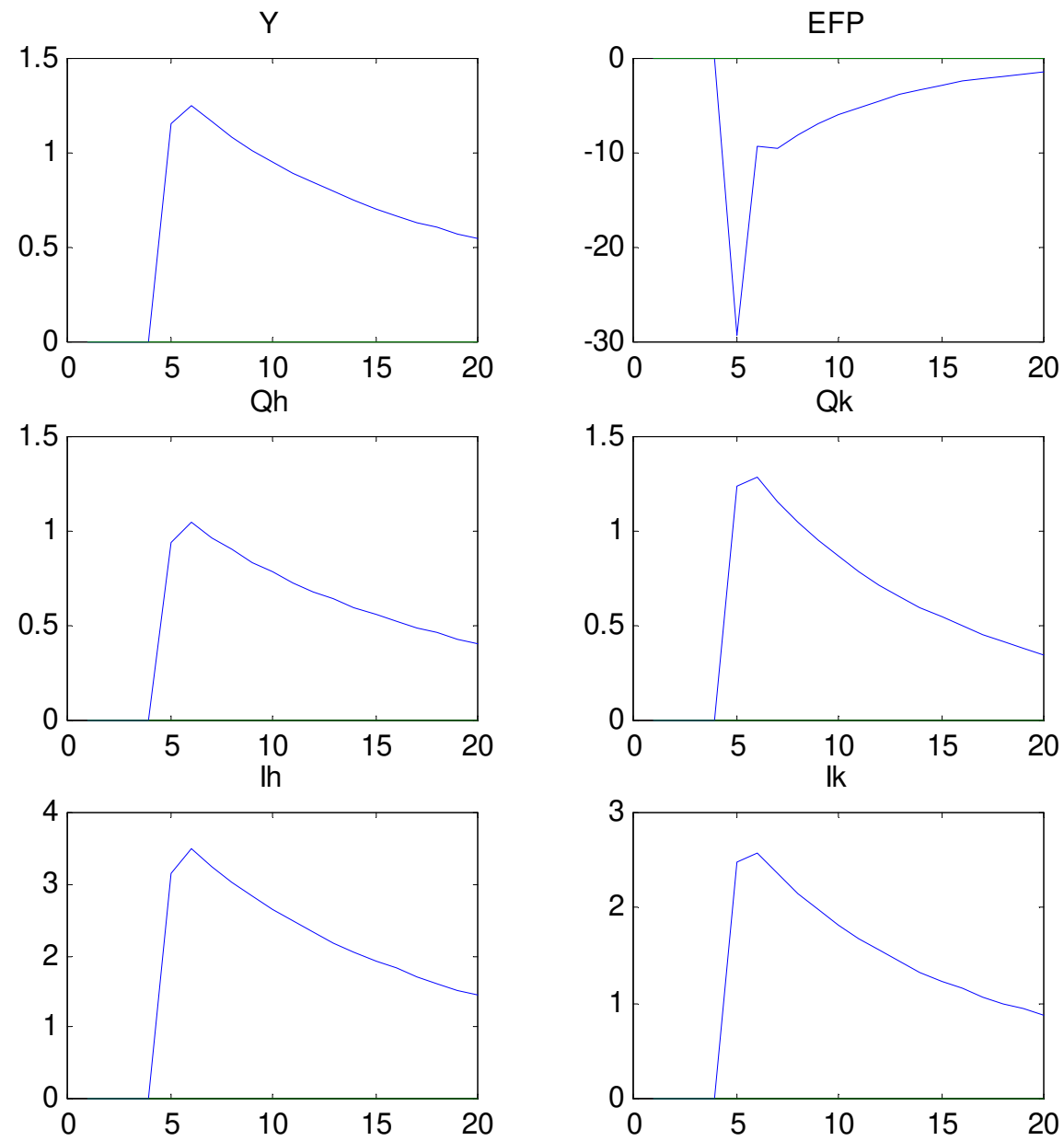

Figure 3a. Impulse responses to one standard deviation productivity shock.

Note: $Y$ : aggregate output, $E F P$ : external finance premium, $Q^{h}$ : house price, $Q^{k}$ : capital price, $I^{h}$ : house investment, $I^{k}$ : capital investment. All plots are in terms of percentage deviations from the corresponding steady states, except that $E F P$ is in terms of basis point deviation. 

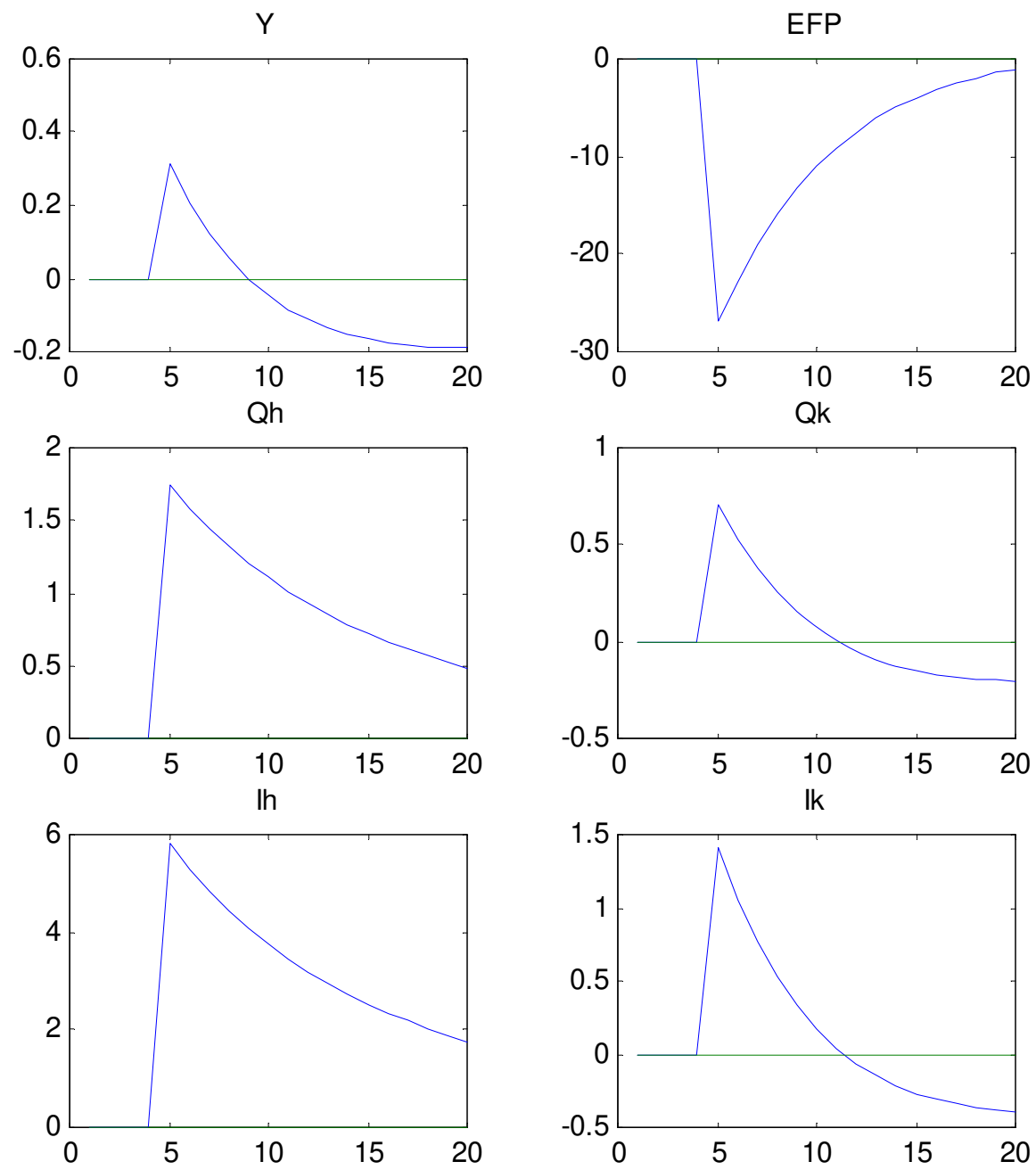

Figure 3b. Impulse responses to one standard deviation house demand shock.

Note: $Y$ : aggregate output, EFP: external finance premium, $Q^{h}$ : house price, $Q^{k}$ : capital price, $I^{h}$ : house investment, $I^{k}$ : capital investment. All plots are in terms of percentage deviations from the corresponding steady states, except that $E F P$ is in terms of basis point deviation. 